\title{
Risk factors for unsuccessful vaginal birth after caesarean at full dilatation
}

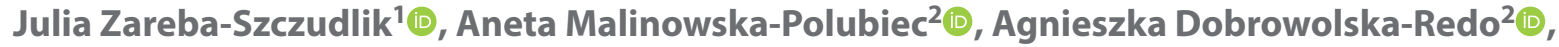 \\ Zbigniew Lewandowski², Joanna Kacperczyk-Bartnik² ${ }^{\mathbb{D}}$, Pawel Bartnik ${ }^{2} \mathbb{D}$, \\ Ewa Romejko-Wolniewicz² ${ }^{\circledR}$ \\ ${ }^{1}$ The Institute of Mother and Child, Warsaw, Poland \\ ${ }^{2} 2^{\text {nd }}$ Department of Obstetrics and Gynecology, Medical University of Warsaw, Poland
}

\begin{abstract}
Objectives: The purpose of this study was to determine the risk factors for caesarean sections in the second stage of labour after a previous caesarean section among women who underwent trial of labour (TOL).

Material and methods: From a total of 639 women who experienced one caesarean section, 456 women were qualified for TOL. From this group, 105 women were subjected to a caesarean section in the first stage of labour and another 351 women reached the second stage of labour. From the latter group, 309 women delivered naturally and 42 were subjected to a caesarean section.

Results: Risk factors for the necessity of performing a caesarean section in the second stage of labour after a previous caesarean section was the weight gain during pregnancy $(O R=1.07)$, the height of fundus uteri $(O R=1.25)$ before delivery, and the estimated foetal weight $(\mathrm{OR}=1.01)$, a past delivery of a child with a birth weight exceeding $4.000 \mathrm{~g}(\mathrm{OR}=2.14)$, the presence of pre-gestational diabetes $(O R=15.4)$ and gestational diabetes $(O R=2.22)$, necessity of applying a delivery induction $(O R=2.52)$, stimulation of uterine activity during delivery $(O R=2.43)$ and application of epidural analgesia $(O R=4.04)$. A factor reducing the risk of a caesarean section in the second stage was a vaginal delivery in a woman's history $(O R=0.21)$. Conclusions: Women should be encouraged to deliver naturally after a previous caesarean section, especially when their history includes a vaginal delivery and if there is no need for labour induction.
\end{abstract}

Key words: caesarean section; repeat; trial of labour; vaginal birth after caesarean

Ginekologia Polska 2021; 92, 1:24-29

\section{INTRODUCTION}

For the last few decades, the number of caesarean sections has been growing consistently, up to $32.7 \%$ in the USA, $22.0 \%$ in Great Britain, $37.4 \%$ in Italy, and $41.3 \%$ in Brazil in 2013 [1, 2]. In Poland, over 1/3 of deliveries result in a caesarean section [3].

A reason for this seems to be a liberalization of indications for a caesarean section, along with the gradually decreasing risk of complications during such a surgery. A rule that has been valid since the 1970s,"caesarean section once, caesarean section always", is no longer enforced. However, it should be accepted that managing a vaginal delivery after a caesarean section requires considerable experience from an obstetrician, and an appropriate qualification for a natural delivery is the key to success [4].

The percentage of women qualified for a trial of labour (TOL), for whom there is a necessity of performing another caesarean section in the second stage of delivery is relatively high. Caesarean sections performed at full dilatation are technically difficult procedures and trigger an increased risk of complications for a mother and foetus $[5,6]$.

\section{Objectives}

The purpose of this study was to determine the risk factors for caesarean sections in the second stage of labour after a previous caesarean section among women who underwent a trial of vaginal delivery.

\section{MATERIAL AND METHODS}

Analyses were performed among women delivering in the 2nd Department of Obstetrics and Gynaecology of the Medical University of Warsaw over a three-year period. Risk factors were searched within a group of patients who had already undergone one caesarean section, qualified for a natural delivery and reached full cervical dilation.

Within this period, 742 women with a single pregnancy, who experienced at least one caesarean section, were admitted for delivery. Out of them, 103 (13.9\%) experienced 


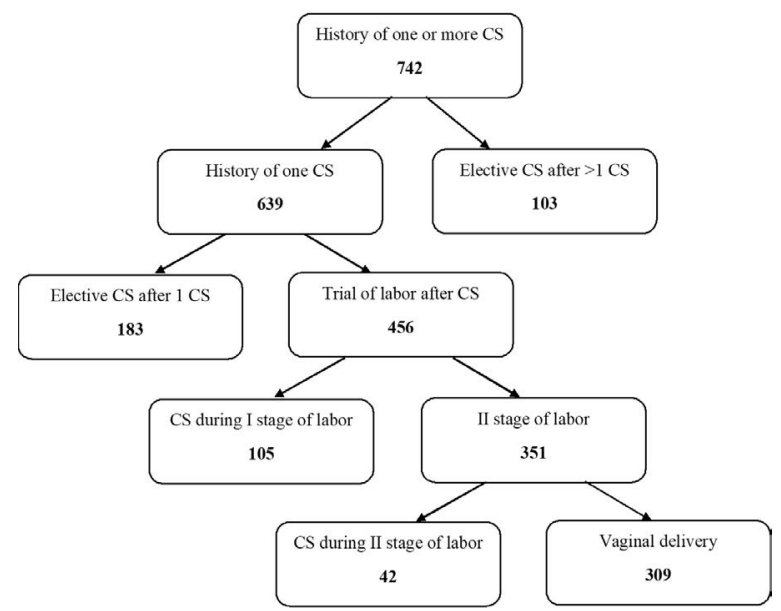

Figure 1. Study population

more than one caesarean section and were excluded from the analyses. Out of 639 women, who experienced one caesarean section, 183 (28.6\%) were qualified for a repeated caesarean delivery (excluded from the analyses), and 456 were qualified for TOL. Out of 456 women qualified for TOL, 105 had caesarean section performed in the first stage of labour and 351 reached the second stage of labour. From the latter group 309 women delivered naturally and 42 were qualified for a caesarean section (Fig. 1).

The following potential risk factors for a caesarean section in the second stage of labour among patients after one caesarean delivery who underwent TOL were assessed: maternal age and gestational age at delivery, maternal anthropometric indices (pre-pregnancy weight, height and body mass index (BMI), gestational weight gain, pre-partum bodyweight, abdominal circumference and height of fundus uteri before delivery), reproductive history (the number and methods of previous deliveries, miscarriages and ectopic pregnancies, the history of the delivery large babies with a birth weight exceeding $4.000 \mathrm{~g}$ ), the course of pregnancy (smoking tobacco, presence of gestational and pre-gestational diabetes, pre-gestational and pregnancy-induced hypertension, intrahepatic cholestasis of pregnancy, thyroid diseases, uterine fibroids, symptoms of threatened premature birth, preterm premature rupture of membranes, antenatal steroid therapy, presence of anaemia based on the mother's haemoglobin concentration prior to delivery), the course of delivery (delivery induction, stimulation of uterine activity, presence of fever $>38^{\circ} \mathrm{C}$, application of epidural analgesia). An estimated foetal weight (EFW) evaluated in ultrasound up to seven days prior to delivery was also considered a potential risk factor.

Mean values and standard deviations or medians and maximum and minimum values of quantitative factors were determined, and a percentage distribution of qualitative factors within an analysed group of women was calculated. An odds ratio (OR) and $95 \%$ confidence interval were determined for each of the analysed risk factor. A value of $p<0.05$ was assumed to be statistically significant. Statistical analysis was executed with using the SAS program $[7,8]$. The study was approved by local Ethical Board.

\section{RESULTS}

Indications for a previous caesarean section within a group of 309 women who delivered naturally and 42 women who delivered by caesarean section during the second stage of labour are included in Table 1.

Repeated caesarean sections in the second stage of labour were performed based on the following indications: lack of delivery progress, 24 women (57.1\%); foetal distress,

\begin{tabular}{|l|l|l|}
\hline \multicolumn{2}{|l|}{ Table 1. Indications for the previous caesarean section } & \\
\hline Indication & $\begin{array}{l}\text { Vaginal delivery after caesarean } \mathbf{( n = 3 0 9 )} \\
\mathbf{n}(\%)\end{array}$ & $\begin{array}{l}\text { Caesarean section in the second stage TOL } \\
(\mathbf{n}=\mathbf{4 2}) \mathbf{n}(\%)\end{array}$ \\
\hline Foetal asphyxia in the first stage of labour & $100(32.4 \%)$ & $11(26.2 \%)$ \\
\hline Non-vertex foetal presentation & $67(21.7 \%)$ & $2(4.8 \%)$ \\
\hline Prolonged first stage of labour & $50(16.2 \%)$ & $11(26.2 \%)$ \\
\hline Prolonged second stage of labour & $26(8.4 \%)$ & $8(19.0 \%)$ \\
\hline Vaginal bleeding in the first stage of labour & $20(6.6 \%)$ & $3(7.1 \%)$ \\
\hline Maternal disease & $14(4.5 \%)$ & 0 \\
\hline Placenta previa & $9(2.9 \%)$ & 0 \\
\hline Cephalopelvic disproportion & $8(2.6 \%)$ & $3(7.1 \%)$ \\
\hline Foetal asphyxia in the second stage of labour & $4(1.3 \%)$ & $1(2.4 \%)$ \\
\hline Foetal disease & $4(1.3 \%)$ & 0 \\
\hline Intrauterine infection & $2(0.6 \%)$ & 0 \\
\hline Vaginal bleeding in the second stage of labour & 0 & $1(2.4 \%)$ \\
\hline Others & $5(1.6 \%)$ & $2(4.8 \% 0$ \\
\hline
\end{tabular}


16 women (38.1\%); vaginal bleeding, 2 women (4.8\%). Among women who delivered vaginally, 24 had an operative vaginal delivery with obstetric vacuum extractor. Indications for a vaginal intervention delivery were the following: foetal distress, 17 women (70.8\%); lack of delivery progress, 6 women (25.0\%); and maternal heart disease, 1 woman (4.2\%).

The following risk factors influencing the necessity of performing a caesarean section in the second period of delivery during TOL were found: gestational weight gain $(O R=1.07)$, the height of fundus uteri before delivery $(O R=1.25)$, an ectopic pregnancy in a woman's history $(\mathrm{OR}=7.67)$, a past delivery of a child with a birth weight exceeding $4.000 \mathrm{~g}(\mathrm{OR}=2.14)$, the presence of pre-gestational diabetes $(O R=15.4)$ or gestational diabetes $(\mathrm{OR}=2.22)$, the delivery induction $(\mathrm{OR}=2.52)$, and stimulation of uterine activity $(\mathrm{OR}=2.43)$, the presence of fever during delivery $(O R=10.3)$, the application of epidural analgesia $(\mathrm{OR}=4.04)$, and EFW (OR=1.01).

A considerable non-linear dependency between the necessity of performing a caesarean section in the second period of labour and the gestational age was found. This risk was five times higher if a delivery occurred prior to a completed $32^{\text {nd }}$ pregnancy week $(O R=5.04)$ and over two times higher if a delivery occurred after the $36^{\text {th }}$ pregnancy week $(\mathrm{OR}=2.62)$ in comparison with a delivery within a period between the $32^{\text {nd }}$ and $36^{\text {th }}$ weeks of pregnancy.

The factor reducing the risk of a caesarean section in the second stage of labour was a vaginal delivery in a woman's history $(O R=0.21)$. The results are presented in Table 2 .

\section{DISCUSSION}

The number of caesarean sections performed in the second stage of labour increases along with the growing percentage of caesarean sections overall [9]. It reaches $6 \%$ according to a report of the Royal College of Obstetricians and Gynaecologists [10]. Various factors seem to determine such a situation. A lack of sufficient experience of an obstetrician in managing operative vaginal deliveries along with growing concerns related to an increased risk of complications among mothers and infants and resulting claims are issues that can significantly impact the number of caesarean sections performed in the second stage of delivery [11].

It should be emphasized that an additional factor increasing the risk of delivery with intervention is a history of previous caesarean section. Fifty-one point six percent of women delivering after one caesarean section had a second caesarean section, of which $55.5 \%$ had an elective one and $44.5 \%$ during a natural delivery, including $31.8 \%$ in the first and $12.7 \%$ in the second stage of delivery.

Lewkowitz et al. [12] determined that nearly half of women after caesarean sections due to the delivery arrest in the first or second stages have a chance for a natural delivery in the next pregnancy. Our results agree with this finding. The authors did not find any differences concerning the chances for a vaginal delivery depending on the lack of progress in the first versus second stage of labour. In our data, among women who delivered vaginally, $16.2 \%$ had a previous caesarean section due to delivery arrest in the first stage of labour and $8.4 \%$ in the second stage. These percentages equalled $25.0 \%$ and $19.0 \%$, respectively, in women who had a caesarean section in the second stage. According to Davis et al. [9], the most common indication for a caesarean section in the second stage is delivery arrest, which also agrees with our results.

In our research, $5.0 \%$ of women after a caesarean section qualified for a TOL, were delivered with the use of an obstetric vacuum extractor due to foetal distress or prolonged second stage. According to the most recent data, a delivery with a such intervention in women after a caesarean section during TOL at a foetal station of at least +2 is a safe procedure [13].

Our analyses did not show that the mother's age, height, weight and BMI prior to pregnancy have any influence on the risk of a caesarean section in the second stage during TOL. Bujold et al. found that the mother's age equal to or exceeding 35 years reduces her chances for natural delivery after a caesarean section not only in women who did not have a natural delivery in their history $[\mathrm{OR}=0.73,95 \%$ confidence interval (Cl): 0.56-0.94] but also in women who had a natural delivery $(\mathrm{OR}=0.47,95 \% \mathrm{Cl}: 0.29-0.74)$ [14]. According to scientists from the other centre in our country, such parameters as maternal age, $\mathrm{BMI}$ and gestational weight gain did not change the percentage of women who delivered vaginally after one caesarean section during TOL [15].

Our data showed that gestational weight gain, maternal abdominal circumference prior to delivery and height of fundus uteri influenced the risk of a caesarean section during TOL. According to American authors, both excessive bodyweight growth during pregnancy and classification as overweight and obesity reduce the chances for a natural delivery after caesarean section [16]. Durnwald et al. [17] also found that women who were obese prior to pregnancy had a lower chance of delivering naturally after a caesarean section.

A history of ectopic pregnancy increased the risk of caesarean section in the second stage during TOL by over seven times. In the case of a previous delivery of the large baby the risk increased by twice. Unfortunately, there are no data in the literature concerning these issues. It seems that in such cases an obstetrician decides more easily to perform a caesarean section in the second stage of the delivery.

We found that occurrence of pre-gestational diabetes increased the risk of caesarean section in the second period of delivery by more than 15 times and that gestational 
Table 2. Perinatal risk factors for caesarean section in the second stage of labour in women after previous caesarean

\begin{tabular}{|c|c|c|c|c|}
\hline & mean $\pm S D(\min -\max )$ or $n(\%)$ & OR (95\% Cl) & $\mathbf{P}_{\text {lin }}$ & $\mathbf{P}_{\text {non lin }}$ \\
\hline $\begin{array}{l}\text { Quantitative: } \\
\text { Maternal and fetal data: } \\
\text { Age [years] }\end{array}$ & $31.5 \pm 4.3(17-45)$ & $1.20(0.95-1.10)$ & NS & NS \\
\hline Gestational age [weeks] & $38.3 \pm 2.7(24-42)$ & $0.70(0.87-1.09)$ & NS & 0.015 \\
\hline Pre-pregnancy weight [kg] & $63.4 \pm 13.2(40-153)$ & $1.02(0.99-1.04)$ & NS & NS \\
\hline Height $[\mathrm{cm}]$ & $164.8 \pm 6.0(146-181)$ & $0.97(0.91-1.02)$ & NS & NS \\
\hline Pre-pregnancy BMI [kg/m2] & $23.3 \pm 4.5(16.0-55.5)$ & $1.03(0.99-1.04)$ & NS & NS \\
\hline Gestational weight gain [kg] & $13.5 \pm 4.8(0-28)$ & $1.07(0.99-1.15)$ & 0.046 & NS \\
\hline Pre-partum weight [kg] & $76.9 \pm 13.2(55-159)$ & $1.02(0.99-1.04)$ & NS & NS \\
\hline Abdominal circumference $[\mathrm{cm}]$ & $103.5 \pm 8.4(84-142)$ & $1.07(1.03-1.11)$ & 0,001 & NS \\
\hline Fundal height $[\mathrm{cm}]$ & $35.9 \pm 3.8(24-48)$ & $1.25(1.13-1.38)$ & 0.001 & NS \\
\hline Estimated fetal weight [g] & $3199.8 \pm 590.0(660-4244)$ & $1.01(0.99-1.01)$ & 0.040 & NS \\
\hline Pre-partum hemoglobin level $[\mathrm{g} / \mathrm{L}]$ & $12.4 \pm 1.0(8.5-15.3)$ & $1.34(0.96-1.85)$ & NS & NS \\
\hline $\begin{array}{l}\text { Qualitative: } \\
\text { Previous vaginal delivery }\end{array}$ & 75 (21.4\%) & $0.21(0.05-0.81)$ & 0.024 & \\
\hline History of spontaneus abortion & $82(23.4 \%)$ & $1.03(0.64-1.65)$ & NS & \\
\hline History of ectopic pregnancy & $4(1.1 \%)$ & $7.67(1.05-56.0)$ & 0.045 & \\
\hline Previous LGA baby & $55(15.7 \%)$ & $2.14(1.01-4.58)$ & 0.049 & \\
\hline GDM in current pregnancy & $65(18.5 \%)$ & $2.22(1.08-4.55)$ & 0.03 & \\
\hline Pre-gestational diabetes & $3(0.9 \%)$ & $15.40(1.37-173.68)$ & 0.027 & \\
\hline $\mathrm{PIH}$ in current pregnancy & $18(5.1 \%)$ & $1.51(0.42-5.44)$ & NS & \\
\hline Pre-pregnancy hypertension & $15(4.3 \%)$ & $1.14(0.25-5.23)$ & NS & \\
\hline Cholestasis in current pregnancy & $17(4.8 \%)$ & $0.45(0.06-3.46)$ & NS & \\
\hline Thyroid disorders & $29(8.3 \%)$ & $0.52(0.12-2.28)$ & NS & \\
\hline Threatened preterm birth in current pregnancy & $25(7.1 \%)$ & $0.62(0.14-2.74)$ & NS & \\
\hline PPROM in current pregnancy & $94(26.8 \%)$ & $0.42(0.17-1.03)$ & NS & \\
\hline Antenatal steroid therapy in current pregnancy & $36(10.3 \%)$ & $0.64(0.19-2.20)$ & NS & \\
\hline Myomas & $4(1.1 \%)$ & $2.49(0.25-24.48)$ & NS & \\
\hline Smoking status during pregnancy & $57(16.2 \%)$ & $1.78(0.78-4.04)$ & NS & \\
\hline Labor induction & $102(29.1 \%)$ & $2.52(1.31-4.85)$ & 0.006 & \\
\hline Augmentation of labor & $177(50.4 \%)$ & $2.43(1.22-4.84)$ & 0.012 & \\
\hline Fever in labor & $9(2.6 \%)$ & $10.30(2.65-40.06)$ & 0.001 & \\
\hline Epidural analgesia & $154(45.0 \%)$ & $4.04(1.83-8.91)$ & 0.001 & \\
\hline
\end{tabular}

$\mathrm{BMI}$ — body mass index; LGA — large for gestational age; GDM — gestational diabetes mellitus; PIH — pregnancy induced hypertension; PPROM — preterm premature rupture of membranes

diabetes increased this risk by more than twice. Blackwell et al. [18] already found that a mother with diabetes has reduced chances for a natural delivery after a caesarean section. American authors who analysed the chances of having a natural delivery after a caesarean section among women with diabetes in accordance with White's classification determined that $68.5 \%$ of women in class $\mathrm{A} 1$ delivered vaginally after a caesarean section, $55 \%$ in class $A 2,70.0 \%$ in class $B$, $47.6 \%$ in class $C$, and $12.5 \%$ in class D/F/R [19].

According to our results, when qualifying a woman after a caesarean delivery for a natural delivery, higher EFW in USG should be considered as a factor reducing the chanc- es for success in the second period of delivery. According to American authors, the frequency of natural deliveries among women after a caesarean section was the same among women who delivered children with a bodyweight equal or greater than $4.000 \mathrm{~g}(73.0 \%)$ in comparison with women who delivered smaller children (76.0\%) [20]. However, Zelop et al. claimed that the bodyweight of an infant being equal to or greater than $4.000 \mathrm{~g}$ increases the risk of another caesarean section by 1.7 times (95\% Cl: 1.3-2.2) [21]. Phelan et al. [22] analysed the TOL among women after a caesarean section who delivered infants with bodyweights equal to or greater than $4.000 \mathrm{~g}$. The percentage 
of natural deliveries within this group equalled $67.0 \%$, and a factor that decreased the chances for a successful natural delivery was an indication for a previous caesarean section due to a cephalopelvic disproportion. This was also confirmed by Elkousy et al. and Kalok et al. [23, 24]. Based on the results above, it could be claimed that the awareness that a woman undergoing a trial of natural delivery after a caesarean section may have a heavy child forces an obstetrician to repeat a caesarean section even during the second period of delivery.

It should also be mentioned that among women after a caesarean section, delivery ending with a caesarean section in the second period occurred more often prior to completing the $32^{\text {nd }}$ week of pregnancy and after completing the 36th week of pregnancy. Hammoud et al. [25], analysed three groups of women qualified for TOL after a caesarean section: $24-36$ weeks and 6 days, 37-40 weeks and 6 days and $\geq 41$ weeks of pregnancy. The authors determined that advanced gestational age was related to decreased chances for a vaginal delivery $(\mathrm{OR}=0.68,95 \% \mathrm{Cl}$ : $0.51-0.89)$ and increased risk of uterine rupture $(O R=2.85$, $95 \% \mathrm{Cl}: 1.27-6.42$ ) in comparison to $37-40$ weeks and 6 days gestational age.

We found that a risk of caesarean section in the second period of delivery among women after a caesarean section was increased by delivery induction, stimulation of uterine activity with oxytocin and epidural analgesia. Sakala et al. [26] evaluated the use of oxytocin to induce delivery or stimulate uterine activity among patients after a caesarean section and obtained results similar to ours: $68.0 \%$ of women treated with oxytocin delivered naturally in comparison to $89.0 \%$ of women who were not given oxytocin. This result has also been confirmed in other studies [22]. Antonakou et al. [27] analysed the influence of an epidural analgesia throughout the course of delivery among women who experienced delivery induction. They found that the application of an epidural analgesia did not increase the risk of caesarean section; however, it increased the risk of operative vaginal delivery (adjusted $\mathrm{OR}=3.63 ; 95 \% \mathrm{Cl}$ : 2.51-5.24; $\mathrm{p}<0.001$ ) and extended the first and second periods of delivery. Other authors also did not find any relationship between the application of an epidural analgesia and an increased risk of caesarean section, whereas some scientific studies have suggested that epidural analgesia may extend the second period of delivery [26, 28, 29].

Davis et al. found that a caesarean section in the second period of delivery was usually performed in women who had a delivery for the first time [9]. We found that a factor that decreased the risk of caesarean section by $79.0 \%$ after previous caesarean section was a vaginal delivery in a woman's history. Hendler and Bujold stated that history of a vaginal delivery, especially after a caesarean section, increased chances for a natural delivery after a caesarean section $[14,30]$.

\section{CONCLUSIONS}

To conclude, it should be emphasized that women should be encouraged to try to deliver naturally after a previous caesarean section, especially when their history includes a vaginal delivery and if there is no need for labour induction. However, women with high weight gain during pregnancy, suspicion of macrosomia in an ultrasound scan, a previous large baby, women with diabetes or those requiring labour induction should be qualified very carefully for a natural delivery after a previous caesarean section because their risk of caesarean section in the second stage of labour is higher.

\section{REFERENCES}

1. Henke RM, Wier LM, Marder WD, et al. Geographic variation in cesarean delivery in the United States by payer. BMC Pregnancy Childbirth. 2014; 14: 387, doi: 10.1186/s12884-014-0387-x, indexed in Pubmed: 25406813.

2. World Health Organization. World health statistics 2010. https://www. aidsdatahub.org/sites/default/files/documents/WHO_2010_World_ Health_Statistics_2010.pdf.

3. Stasiełuk A, Langowicz I, Kosińska-Kaczyńska K, et al. Is the epidemic of cesarean sections the result of more liberal indications? Ginekol Pol. 2012; 83(8): 604-608.

4. Romejko-Wolniewicz E, Gorsiak A, Zaręba-Szczudlik J, et al. Poród po cięciu cesarskim - kiedy należy się obawiać [Labor after cesarean delivery - when should we be afraid]. Klin Perinatol i Gin. 2007; 43(4): 21-28.

5. Unterscheider J, McMenamin M, Cullinane F. Rising rates of caesarean deliveries at full cervical dilatation: a concerning trend. Eur J Obstet Gynecol Reprod Biol. 2011; 157(2): 141-144, doi: 10.1016/j.ejogrb.2011.03.008, indexed in Pubmed: 21470764.

6. Lurie $\mathrm{S}, \operatorname{Raz} \mathrm{N}$, Boaz M, et al. Comparison of maternal outcomes from primary cesarean section during the second compared with first stage of labor by indication for the operation. Eur J Obstet Gynecol Reprod Biol. 2014; 182: 43-47, doi: 10.1016/j.ejogrb.2014.08.025, indexed in Pubmed: 25218551.

7. Inc SI. SAS/STAT ${ }^{\oplus}$ 9.3, User's Guide, Volume 1, 2, 3. Cary, NC, USA,2011.

8. Fisher L, Van Be. Biostatistics: a methodology for the Health Sciences. John Wiley \& Sons, Inc 1994.

9. Davis $G$, Fleming $T$, Ford $K$, et al. Caesarean section at full cervical dilatation. Aust N Z J Obstet Gynaecol. 2015; 55(6): 565-571, doi: 10.1111/ajo.12374, indexed in Pubmed: 26223774.

10. Thomas J, Paranjothy S. Royal College of Obstetricians and Gynaecologists Clinical Effectiveness Support Unit. National Sentinel Caesarean Section Audit Report. RCOG press, London 2001.

11. Senturk MB, Cakmak Y, Atac $\mathrm{H}$, et al. Factors associated with successful vaginal birth after cesarean section and outcomes in rural area of Anatolia. Int JWomens Health. 2015; 7: 693-697, doi: 10.2147/IJWH.S83800, indexed in Pubmed: 26203286.

12. Lewkowitz AK, Nakagawa S, Thiet MP, et al. Effect of stage of initial labor dystocia on vaginal birth after cesarean success. Am J Obstet Gynecol. 2015; 213(6): 861.e1-861.e5, doi: 10.1016/j.ajog.2015.08.064, indexed in Pubmed: 26348381.

13. Son M, Roy A, Grobman WA. Attempted operative vaginal delivery vs repeat cesarean in the second stage among women undergoing a trial of labor after cesarean delivery. Am J Obstet Gynecol. 2017; 216(4): 407.e1407.e5, doi: 10.1016/j.ajog.2017.01.013, indexed in Pubmed: 28153660.

14. Bujold E, Hammoud AO, Hendler I, et al. Trial of labor in patients with a previous cesarean section: does maternal age influence the outcome? Am J Obstet Gynecol. 2004; 190(4): 1113-1118, doi: 10.1016/j. ajog.2003.09.055, indexed in Pubmed: 15118651.

15. Micek M, Kosinska-Kaczynska K, Godek B, et al. Birth after a previous cesarean section-what is most important in making a decision. Neuro Endocrinol Lett. 2014; 35(8): 718-723. 
16. Juhasz G, Gyamfi C, Gyamfi P, et al. Effect of body mass index and excessive weight gain on success of vaginal birth after cesarean delivery. Obstet Gynecol. 2005; 106(4): 741-746, doi: 10.1097/01. AOG.0000177972.32941.65, indexed in Pubmed: 16199630.

17. Durnwald CP, Ehrenberg HM, Mercer BM. The impact of maternal obesity and weight gain on vaginal birth after cesarean section success. Am J Obstet Gynecol. 2004; 191(3): 954-957, doi: 10.1016/j.ajog.2004.05.051, indexed in Pubmed: 15467571

18. Blackwell SC, Hassan SS, Wolfe HM, et al. Vaginal birth after cesarean in the diabetic gravida. J Reprod Med. 2000; 45(12): 987-990, indexed in Pubmed: 11153259.

19. Cormier C, Landon M, Lai Y, et al. White's Classification of Maternal Diabetes and Vaginal Birth After Cesarean Delivery Success in Women Undergoing a Trial of Labor. Obstet Gynecol. 2010; 115(1): 60-64, doi: 10.1097/aog.0b013e3181c534ca.

20. Nguyen TV, Dinh TV, Suresh MS, et al. Vaginal birth after cesarean section at the University of Texas. J Reprod Med. 1992; 37(10): 880-882, indexed in Pubmed: 1479573.

21. Zelop CM, Shipp TD, Repke JT, et al. Outcomes of trial of labor following previous cesarean delivery among women with fetuses weighing >4000 g. Am J Obstet Gynecol. 2001; 185(4): 903-905, doi: 10.1067/mob.2001.117361, indexed in Pubmed: 11641675.

22. Phelan JP, Eglinton GS, Horenstein JM, et al. Previous cesarean birth. Trial of labor in women with macrosomic infants. J Reprod Med. 1984; 29(1): 36-40, indexed in Pubmed: 6708019.

23. Elkousy MA, Sammel $M$, Stevens $E$, et al. The effect of birth weight on vaginal birth after cesarean delivery success rates. Am J Obstet Gynecol. 2003; 188(3): 824-830, doi: 10.1067/mob.2003.186, indexed in Pubmed: 12634665.
24. Kalok A, Zabil SA, Jamil MA, et al. Antenatal scoring system in predicting the success of planned vaginal birth following one previous caesarean section. J Obstet Gynaecol. 2018; 38(3): 339-343, doi: 10.1080/01443615.2017.1355896, indexed in Pubmed: 29017359.

25. Hammoud A, Hendler I, Gauthier RJ, et al. The effect of gestational age on trial of labor after Cesarean section. J Matern Fetal Neonatal Med. 2004; 15(3): 202-206, doi: 10.1080/14767050410001668329, indexed in Pubmed: 15280148.

26. Sakala EP, Kaye S, Murray RD, et al. Oxytocin use after previous cesarean: why a higher rate of failed labor trial? Obstet Gynecol. 1990; 75(3 Pt 1): 356-359.

27. Antonakou A, Papoutsis D. The Effect of Epidural Analgesia on the Delivery Outcome of Induced Labour: A Retrospective Case Series. Obstet Gynecol Int. 2016; 2016: 5740534, doi: 10.1155/2016/5740534, indexed in Pubmed: 27990163.

28. Agrawal D, Makhija B, Arora M, et al. The effect of epidural analgesia on labour, mode of delivery and neonatal outcome in nullipara of India, 2011-2014. J Clin Diagn Res. 2014; 8(10): OC03-OC06, doi: 10.7860/JCDR/2014/9974.4930, indexed in Pubmed: 25478409.

29. Paterson CM, Saunders NS, Wadsworth J. The characteristics of the second stage of labour in 25,069 singleton deliveries in the North West Thames Health Region, 1988. Br J Obstet Gynaecol. 1992; 99(5): 377-380, doi: 10.1111/j.1471-0528.1992.tb13752.x, indexed in Pubmed: 1622908 .

30. Hendler I, Bujold E, Hammoud A, et al. Trial of labor in patients with a previous cesarean section: does maternal age influence the outcome? Am J Obstet Gynecol. 2004; 190(4): 1113-1118, doi: 10.1016/j. ajog.2003.09.055, indexed in Pubmed: 15118651 